\title{
Apoptotic Killing of Breast Cancer Cells by IgYs Produced Against a Small 21 Aminoacid Epitope of the Human TRAIL-2 Receptor
}

\author{
Shaghayegh Amirijavid', Maliheh Entezari', Abolfazl Movafagh' ${ }^{2}$ Mehrdad \\ Hashemi $^{1 *}$, Alireza Mosavi-Jarahi ${ }^{4}$, Hossein Dehghani ${ }^{3 *}$
}

\begin{abstract}
TRAIL, tumor necrosis factor (TNF)-related apoptosis-inducing ligand belongs to one of important cytokine superfamilIES, tumor necrosis factor $(\mathrm{TNF} \alpha)$. TRAIL-2 receptor agonists activate several cell signaling pathways in cells in different manners and could lead to apoptosis or necrosis. Agonistic egg yolk antibodies like IgY which have been developed in a selective manner could activate TRAIL death receptors such as TRAIL-2 (DR5) and thus apoptosis signaling. We here investigated induction of apoptosis in human breast cancer cells (MCF7 cell line) by an IgY produced against an 21 aminoacid epitope of the human TRAIL-2 receptor. As the first step a small peptide of 21 aminoacids choosen from the extracellular domain of DR5 protein was produced with a peptide synthesizer. After control assays and confirmation of the correct amino acid sequence, it was injected to hens immunized to achieve high affinity IgYs. At the next step, the produced IgYs were extracted and examined for specificity against DR5 protein by ELISA assay. Subsequently, the anticancer effect of such IgYs was determined by MTT assay in the MCF7 human breast cancer cell line. The produced peptides successfully immunized hens and the produced antibodies which accumulated in egg yolk specifically recognized the DR5 protein. IgYs exerted significant toxicity and killed MCF7 cells as shown by MTT assay.
\end{abstract}

Keywords: Breast cancer - MCF7 cell line - IgY - chicken yolk immunoglobulin - DR5

Asian Pac J Cancer Prev, 17, Cancer Control in Western Asia Special Issue, 293-297

\section{Introduction}

Cancer is a disease of a genome and normality of cell proliferation. So in these types of cells, several cycles of duplication without right replication cause amplification of mutations. Apoptosis or cell programmed death is a intrinsitic death pathway which is used to regulate cell`s many hemostatic processes. Occupinig the death receptors from TNF $\alpha$ superfamilly such as CD95 or TRAIL receptors by their specific ligands can recruit the subsequent effector molecules like caspase 8 which will lead to performing complex death inducing signal complex (DISC) (Ashkenazi, 20008). In the next step, it will activate, or alternatively permeablize mitochondrial membrane by cleaving Bid and releasing the cytochrome c out of it. At least, both of these two pathways cause apoptosis in cells. Tumor necrosis factor (TNF)-related apoptosis-inducing ligand is currently attracting great interest as a potential anticancer drug. TRAIL, selectively induces apoptosis in cancerous cells by their specialized death inducing receptors.

TRAIL has five different kind of receptors: DR4
(TRAIL-R1) and DR5 (TRAIL-R2) and the decoy receptors DcR1 (TRAIL-R3), DcR2 (TRAIL-R4), and osteoprotegerin (OPG) (LeBlance and Ashkenazi, 2003; Kischkel et al., 2000; Sprick et al., 2000; Bodmer et al., 2000; Kimberley and Screaton, 2004). however, DR4 or DR5 receptor-specific TRAIL variants would permit new and tumor selective therapies. The researcher indicated that DR5 contributes more than DR4 to the overall apoptotic activity of TRAIL in apoptosis signaling of cancer cells (Kelley et al., 2005; Almasan and Ashkenazi, 2003; Ichikawa et al., 2001). There is an increasing interest in the use of chicken egg yolk for polyclonal antibody production for practical and economical reasons (Bollen and Hau, 1996; Svendsen et al., 1994; Tini et al., 2002). The egg yolk antibodies ( $\mathrm{IgY})$ in recent years remarkably used for scientific (Schade et al., 1997), diagnostic (Di Lonardo et al., 2001), prophylactic (Almeida et al., 1998; Sarker et al., 2001) and therapeutic purposes (Lemamy et al., 1999), and $\mathrm{n}$ the other hand for veterinarian therapy against bacteria such as enteropathogenic Escherichia coli (Amaral and Franco, 2002). Several advantages of IgY like, the phylogenetic distance between birds and

${ }^{1}$ Department of Genetics, ${ }^{3}$ Department of Medical Laboratory Sciences, Tehran Medical Sciences Branch, Islamic Azad University, ${ }^{2}$ Department of Medical genetics, School of Medicine, ${ }^{4}$ Department of Epidemiology, Shahid Beheshti University of Medical Sciences, Tehran, Iran.*For correspondence: dehghanih@yahoo.com,mhashemi@iautmu.ac.ir 
mammals, help to increase immune response in host body (birds) in comparison to mammalian hosts (Leslie and Clem, 1969; Hau et al., 1980; Hau et al., 1981). The combination of this two advantages, occupying the death receptor with an antibody that produced in birds, can give a strong weapon against MCF7 cancerous cells. In this study we choosed a small part of the extracellular domain of the DR5-receptor, synthesized it and used for immunization of the hens. At least, we evaluated its effect on breast cancer cells.

\section{Material and Methods}

\section{Peptide production}

A part of the whole protein that contains 21 amino acids (SCKYGQDYSTHWNDLLFCLRC) is produced in peptide synthesis center of National Institute of Genetic Engineering \& Biotechnology, Iran.

\subsection{Immunization of hens}

Immunization of hens was performed in animal house of Pastour institute (Tehran, Iran) with a total $350 \mu \mathrm{g}$ of peptide plus equal volume of Fround adjuvant per animal by intradermal injection in multiple sites of breast, followed by three subsequent boosters.

\section{ELISA}

Ninety-six-well ELISA plates were coated with $20 \mu \mathrm{g}$ of either recombinant synthesized peptide and were incubated coating buffer for one over-night in $4 \mathrm{oC}$. The coating was followed by $60 \mathrm{~min}$ incubation with blocking buffer then incubated for $45 \mathrm{~min}$ with the tested IgY antibody (dilutions 1:100 to 1:1600 were used), then 30 min incubation with secondary antibodies (goat derived anti-hen-IgG), HRP conjugated. We washed the wells in every step for 3 times with PBST (137mM NaCl, $2.7 \mathrm{~m}$ $\mathrm{M} \mathrm{KCl}, 8 \mathrm{mM} \mathrm{Na} 2 \mathrm{HPO} 4,1.46 \mathrm{~m} \mathrm{M} \mathrm{KH} 2 \mathrm{PO} 4,0.05 \%$ Tween-20). In the detection step, citrate buffer plus OPD and hydroxide peroxide as a catalyzer were added and absorbance was measured at either $492 \mathrm{~nm}$.

\section{Isolation and purification of $\operatorname{Ig} Y$}

Isolation of IgY was carried out by separation of the egg yolk from the white part. The egg yolk was added

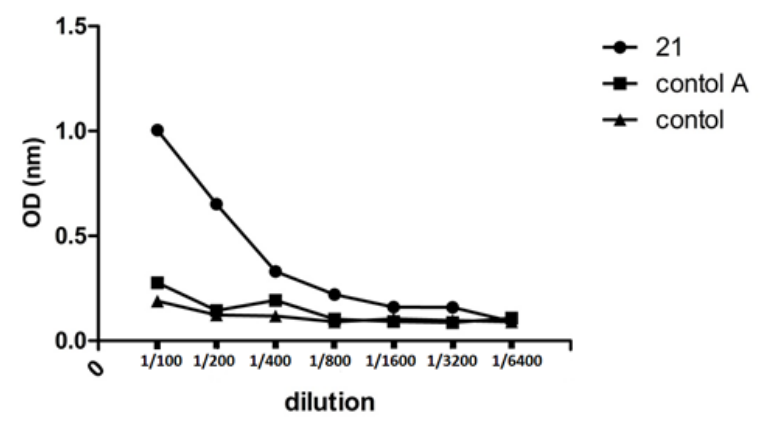

Figure 1. ELISA Result of IgY that Produced Against 21 Amino Acids of the Extracellular Domain of DR5 Protein (IgY-21). ELISA of three kinds of antibody that extracted from the egg with immunization with 21 amino acids (21), with just Fround adjuvant (control A) and without injection (control). P value of 21 , is 0.05 that are according to $\mathrm{p}<0.05$, have sense. two volumes of phosphate buffer (sodium phosphate 0 . $1 \mathrm{M}, \mathrm{NaCl} 10 \mathrm{mM}, \mathrm{pH}=7$ ). To ensure the hemogenising, they were mixed with magnetic stirrer. Then, we added two volume chloroform and incubate in $40 \mathrm{C}$ for 20 minutes. The solution was centrifuged in $14,000 \times \mathrm{g}$, for 20 minutes and the supernatant was collected and the plate was discarded. 12\% (w/v) polyethylene glycol (PEG6,000) was added to the supernatant and mixed with magnetic stirrer for 20 minutes to remove lipoproteins. The mixture was centrifuged at $14,000 \times \mathrm{g}, 10$ minutes at $4 \mathrm{oC}$ and the supernatant was discarded and sediment was resolved in PBS (PH=7.4). For more purification of IgY the last step was repeated for three times. At least, the sediment was resuspended in an equal volume of phosphate buffer and preserved at $4 \mathrm{oC}$ until further use.

\section{SDS-PAGE analysis of $\operatorname{Ig} Y$}

Sodium dodecyl sulphate polyacrylamide Gel Electrophoresis (SDS-PAGE) was carried out according to the method of Laemmli. 9\% PAGE was made using Bio-Rad Mini Protein system. 20 $\mu$ l of IgY-21 and $20 \mu \mathrm{l}$ of $\operatorname{IgY}$ which was isolated and purified from non-immunized hens were separately diluted in $1: 2$ ratio with sample buffer (62.6 mM Tris- $\mathrm{HCl}, \mathrm{pH} 6.8,25 \%$ glycerol [v/v], 2\% SDS [v/v], 5\% $\beta$-mercaptoethanol) and heated at $100 \mathrm{oC}$ for 5 minutes. $20 \mu \mathrm{l}$ from each sample was loaded into each well. Pre-stained protein molecular marker (Fermentas) was used as a standard molecular weight marker.

\section{MTT assay}

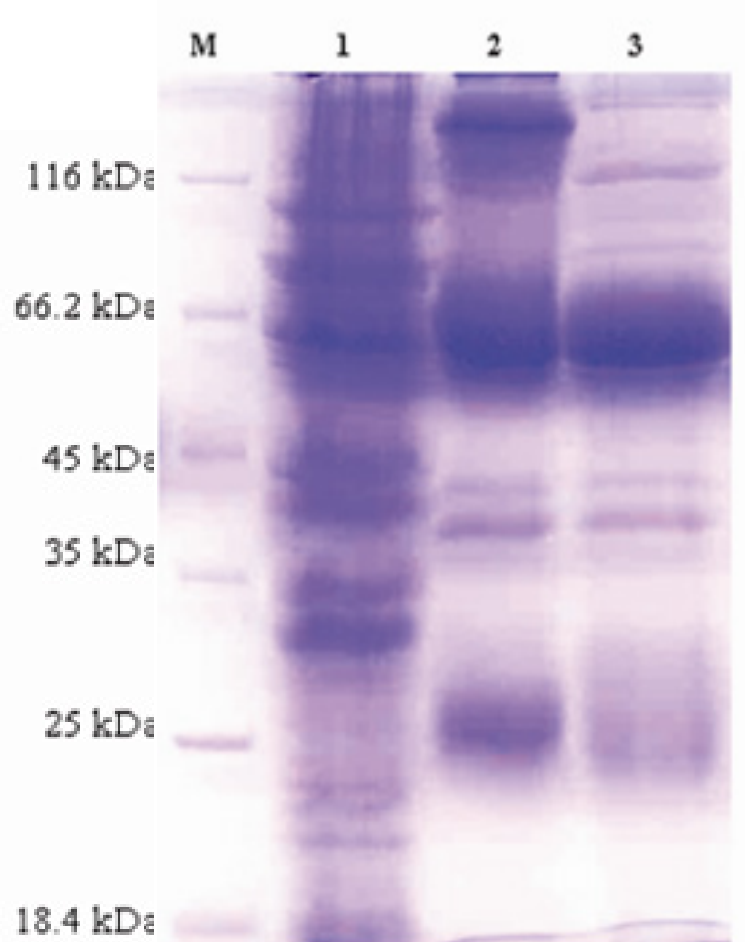

Figure 2. SDS-PAGE (9\%) Analysis of Purified IgY. M, Molecular weight marker; Lane 1, IgY from egg yolk of non-immunized hens; Lane 2, IgY from egg yolk of immunized hens under non-reducing conditions; Lane 3, IgY from egg yolk of immunized hens under reducing conditions. 


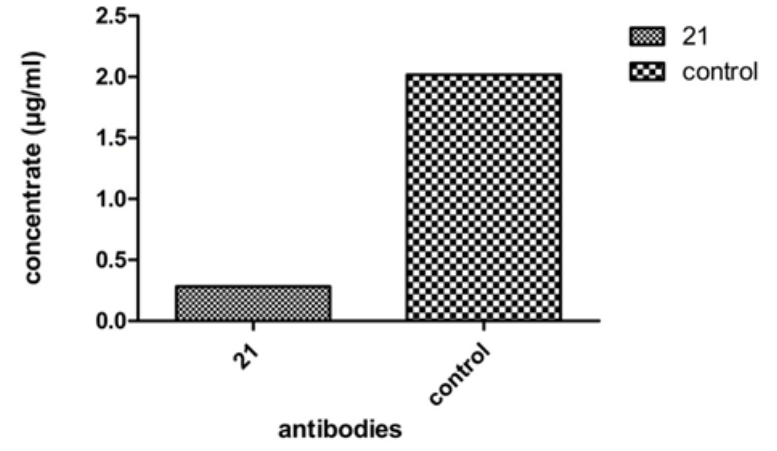

Figure 3. IC50 Dosage of Antibody that Effects on MCF7 Cells. Dosage for killing 50\% of MCF7 cell with IgY-21 (0.07 $\mu \mathrm{g} / \mathrm{ml})$ and control A $(2.02 \mu \mathrm{g} / \mathrm{ml})$; The results assessed with Pharms software.

MTT assay (a colorimetric assay) detects the reduction of MTT (Sigma) by mitochondrial dehydrogenase to blue formazan product, which reflects the normal function of mitochondria and hence the measurement of cytotoxicity of cell and viability. Briefly, 104 cells/well were treat-ed with various concentrations of antibodies (final volume should be $200 \mu \mathrm{l}$ ). After 24 hour incubation the cells were washed twice with phos-phate buffered saline (PBS) and MTT $(0.5 \mathrm{mg} / \mathrm{mL}$ PBS $)$ was added to each well and incubated at $37^{\circ} \mathrm{C}$ for $3 \mathrm{~h}$. The formazan crystals that formed were dissolved by adding dimeth-yl sulfoxide $(100 \mu \mathrm{L} /$ well $)$, and the absorbance was read at $570 \mathrm{~nm}$ using a microplate scanning spectrophotometer (ELISA reader, Organon Teknika, Netherlands). Toxicity level was calculated by the following formula:

Cytotoxicit $\%=1-\frac{\text { Mean absorbance } \phi \text { toxicant }}{\text { Mean absorbance } \phi \text { negative control }} \times 100$

Viability $\%=100$ - Cytotoxicity $\%$

To diminish test error level, MTT strain was added to some wells without cells and along with other wells, absorbance level was read and ultimately subtracted from whole the absorbance.

A

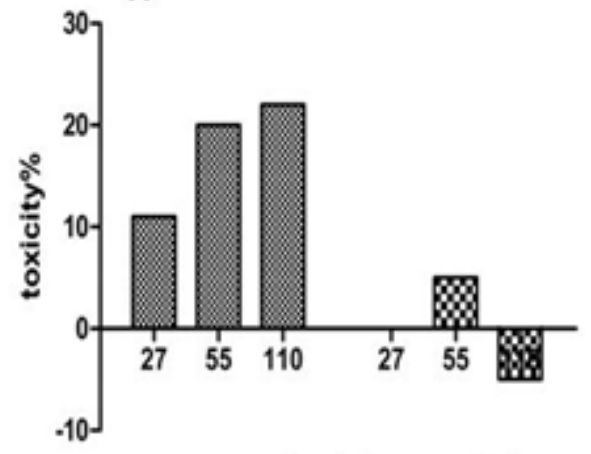

concentration (microgram/ml)
Flowcytometry analysis

$1 \times 106$ cells from MCF7 cancer cell line were incubated under treatment of $0.067 \mu \mathrm{g} / \mathrm{ml}$ of antibodies that produced against 21 amino acids of DR5 protein (mentioned previously). As well as control cells, the treated cells were centrifuged after incubation and they were performed in interval periods of 6 hours. The centrifuge operation was repeated following wash out with PBS. Flowcytometry analysis was accomplished by using Annexin-V-flous staining (Roche) kit. Accordingly after centrifuge, $500 \mu \mathrm{l}$ of Annexin-V-flous binding solution and $5 \mu \mathrm{l}$ from Annexin-V-fluorecein and propidium iodide were added to the cells followed by the cells were incubated in $15-25^{\circ} \mathrm{C}$ for 5 minutes. Lastly, they were analysed by flowcytometer immediately after incubation.

\section{Results}

Efficient production of IgY against little epitope of DR5

To test the production of antibody after immunization period, we performed the ELISA assay with IgY samples. Egg yolk from immunized hens were used for IgY purification. After purification of IgY from egg yolk, we demonstrated that there was a significant amount of antibody in the yolk of the hens. The results shown in figure 1 . As indicated, immunization with $350 \mu \mathrm{g}$ of peptide, efficiently induced antibody secretion. Actually, the produced IgY (IgY-21) in blood at least transferred into yolk and concentrated there. As you can see in Figure 1, in controst to control IgYs, test`s IgY proprietary recognizes DR5 epitope. Control IgYs, the antibodies produced against just Fraund 's adjuvant and the antibodies obtained from nonimmunized hens, had no affinity to our peptide. It was happily confirmed the specificity of IgY-21 against DR5 protein. The purification was assessed using SDS-PAGE under reducing and non-reducing conditions (Figure 2).

\section{IgY-21 kill cancerous cells selectively.}

The MTT cell proliferation assay measures the cell proliferation rate and conversely, when metabolic agents

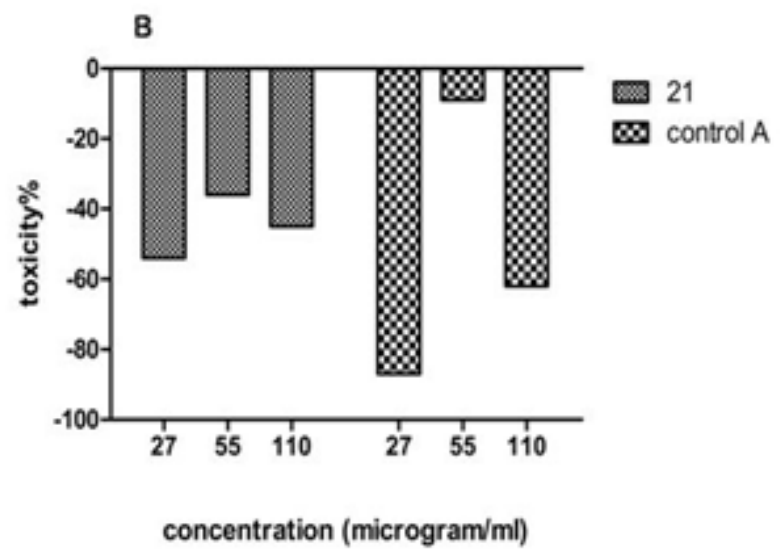

Figure 4. MTT Results (A), Toxicity percentage of IgYs of 21, control A and control, on MCF7 cells; The P- value is 0.02 according to $\mathrm{P}<0.05$ it has no sense; (B), The percentage of toxicity of mentioned antibodies on $3 \mathrm{~T} 3$ cells; $\mathrm{P}$ - value is 0.76 acording to $\mathrm{P}<0.05$ it has no sense; The percentage of toxicity was calculated using the following formula: $\%$ toxicity $=(\mathrm{AT} / \mathrm{AUT}-1) \times 100$, where AT is absorbance of treated cells, and AUT is absobance of untreated cells. 

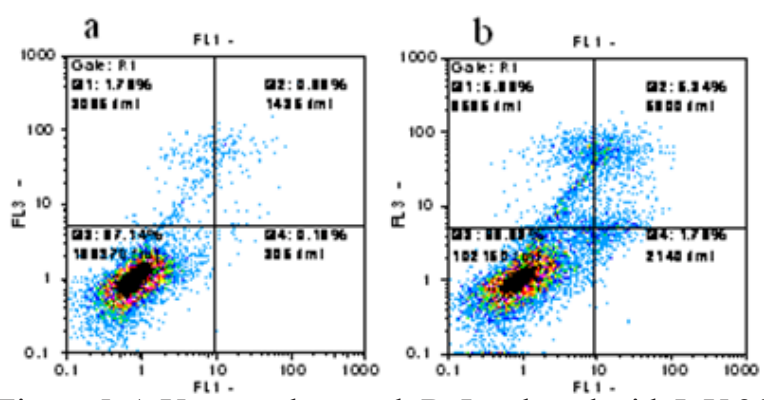

Figure 5. A,Untreated control; B, Incubated with IgY-21; MCF7, humanbreastcancercell lines labelledwithannexin $\mathrm{V}$ and PI; Q2, necrotic cells and cells probbl in second phase of apoptosis; Q3, apoptotic cells; Q4, live cells.

leads to apoptosis or necrosis, it measures the increasing of cell toxicity. To estimate the ability of IgY-21 to kill the cancerous cells, we used the MTT assay. The result showed half of the cells within $0.067 \mu \mathrm{g} / \mathrm{ml}$ of $\operatorname{IgY}-21$ survived (Figure 3 ). We expected such results according to the specific interaction of IgY-21 with DR5 receptor, it seems thet IgY can induce initiation of death cascade in such cells (Figure 4A). It is obvious that IgY-21 efficiently could kill the MCF7 cancerous cell though this dosage does not have any effect on normal mice hepatocyte cells (3T3 cell line) (Figure 4B).

\section{The death that IgY-21 induced is definitely apoptosis.}

Annexin V/PI assay significantly indicates that the attachment of antibody to it's receptor start the apoptotic pathway in cancerous cells. In Figure 5, flowcytometric results indicated apoptotic bodies. In treatment for just 3 hours $8.2 \%$ of treated MCF7 cells in contrast to untreated cells had apoptosis (primery and secondry level of apoptosis).

\section{Discussion}

Nowadays, the researches in wild field of apoptosis due to expanding our knowledge about its special role in clinical trail against tumours. Apoptosis is an energy-dependent process that can actively decrease the improperly developed cells or the cells which have genetic damages (Thompson, 1995). Many oncogenes and suppressor genes that participate in the human cancer pathophysiology, such as Ras and p53, represent overactive or deleted in human cancers. P53 acts such as a gourd in native cells and which upon induction of DNA damage is pivotal in the DNA repair process (Lebedeva et al., 2003). p53 is inactivated in approximately $50 \%$ of human cancers, representing the most common genetic aberration in human malignancy. So, as mentioned cell loses one of the most important key initiators of apoptosis in the cancerous cells. As we wanted to start this process try to find another properly substitute for it. It seems death receptors are a good one. TRAIL is a $32 \mathrm{kDa}$ protein which is expressed in a many cells of normal fetal and adult tissues. Such observations demonstrated that in normal cells there is no toxic effect. The researchers indicated that TRAIL can initiate apoptosis in transformed and malignant cells, but not in normal cells (Lebedeva et al., 2003). The selective nature of the anticancer activity of TRAIL was demonstrated by studies in mice and non-human primates (Ashkenazi, 1995; Walczak et al., 1999). But the reports that indicated the cytotoxic effect of this on normal cells (Jo et al., 2000; Ozoren et al., 2000), suggest the non optimization of this kind of induction (Lawrence et al., 2001). TRAIL-mimicking antibody which is bound to receptor and activate it, can be a good substitute therapy. Nowadays several kind of this antibodies against DR4 and DR5 for treatment of different kind of malignancies are in clinical trials (Salcedo et al., 2002; Chen et al., 2012; gue et al., 2005; Xiang et al., 2013; Du et al., 2011). Though unfortunately, almost all of them could not kill cancerous cells lonely and need the association of chemotraphical treatments.

After Klemperer discovery that the immunization of hens results in transfering the specific IgY from serum to eggs till now, the scientifics produce several kinds of IgYs that can stop or control their target pathological organisms (Chalghoumi et al., 2009; Dias et al., 2010). Beside other benefits of IgYs, chicken antibodies do not activate the mammalian complement system nor interact with rheumatoid factors, or bacterial and human Fc receptors. It seems using the antibody which produced by hens to attaching this receptor and mimicking it's work can be efficient. As we see, the antibody against a small part of the extracellular domain of DR5 receptor could specifically attach and induce its activation.

The 21 amino acid peptide, have cysteine rich repeats that play an important role in the extracellular domain of DR5 receptor. This part plays a special role in the efficient folding of the ligand attachment domain. Furthermore, according to the results we obtained, it seems that occupying this part with the IgY-21, could definitely activate the receptor. Our peptide was small and it couldn't properly stimulate immune response in hens. So the antibodies yields reduced. It would be because of less uptake of peptides with APC cells or presence of less APC cells under dermal parts. But, such little amount when concentrated in egg yolk, we could obtain more antibodies. IgY-21 with high specifity attach the DR5 receptor on cancerous cells and induce death. The flow cytometric results demonstrated that the IgY-21 definitely cause apoptotic death in MCF7 cells. In contrast, this IgY had no cytotoxic effect on hepatocyte cells (3T3), even in this concentration increased cell proliferations. These two interesting results reveal the specifity of $\operatorname{IgY}-21$ to killing cancer cells versus normal cells and indicated that the death was targeted to cancer cells with reduced side-effects, apoptotic pathways.

\section{Acknowledgments}

Tehran medical sciences branch, Islamic Azad University has provided the study with financial support. Also joint research work with Shahid Beheshti University of Medical Sciences. This research work is part of thesis work of Shaghayegh Amirijavid. All authors participated in organization of the manuscript. None declare any conflict of interest with regard to this research 
work.

\section{References}

Amaral JA, De-Franco MT, Carneiro-Sampaio MMS, et al. (2002). Antienteropathogenic Escherichia coli immunoglobulin $\mathrm{Y}$ isolated from eggs laid by immunized Leghorn chickens. Res Vet Sci, 72, 229-34.

Almasan A, Ashkenazi A (2003). po2L/TRAIL: apoptosis signaling, biology, and potential for cancer therapy. Cytokine Growth Factor Rev, 14, 337-48.

Almeida CMC, Kanashiro MM, Filho FBR, et al. (1998). Development of snake antivenom antibodies in chickens and their purification from yolk. Vet Rec, 143, 579-84.

Ashkenazi A, Dixit VM. (1999). Apoptosis control by death and decoy receptors. Curr Opin Chem Biol, 11, 255-60.

Ashkenazi A. (2008). Targeting the extrinisic apoptosis pathway in cancer cytokine growth factor. Cytokine Growth Factor Rev, 19, 325-31.

Bodmer JL, Holler N, Reynard S, et al. (2000). Trail receptor-2 signals apoptosis through FADD and caspase-8. J Nat Cell Biol, 2, 241-3.

Bollen LS, Hau J (1996). Chicken eggs in polyclonal antibody production. Scand J Lab Anim Sci, 23, 85-91.

Chalghoumi R, Beckers Y, Portetelle D, et al. (2009). Hen egg yolk antibodies (IgY), production and use for passive immunization against bacterial enteric infections in chicken: a review. Biotechnol Agron Soc Environ, 13, 295-308.

Chen KF, Chen HL, Liu CY, et al (2012). Dovitinib sencitizes hepatocellular carcinoma cells to TRAIL and tigatuzumab, a novel anti-DR5 antibody, through SHP-1-dependent inhibition of STAT3. Biochem Pharmacol, 83, 769-77.

Dias da Silva W, Tambourgi DV (2010). IgY: A promising antibody for use in immunodiagnostic and in immunotherapy. Vet Immunol Immunopathol, 135, 173-80.

Di-Lonardo M, Marcante L, Poggiali F, et al (2001). Egg yolk antibodies against the E7 oncogenic protein of human papillomavirus type 16. Arch Virol, 146, 117-25.

Du YW, Chen JG, Bai HL, et al (2011). A novel agonistic anti-human death receptor 5 monoclonal antibody with tumoricidal activity induces caspase- and mitochondrial-dependent apoptosis in human leukemia Jurkat cells. Cancer Biother Radiopharm, 26, 143-52.

Guo Y, Chen C, Zheng Y, et al (2005). A novel anti-human DR5 monoclonal antibody with tumoricidal activity induces caspase-dependent and caspase-independent Cell Death Dis, 280, 41940-52.

Hau J, Westergaard JG, Svendsen P, et al (1980). Comparison between pregnancy-associated murine protein-2 (PAMP-2) and human pregnancy specific beta-1-glycoprotein (SP-1). $J$ Reprod Fertil, 60, 115-9.

Hau J, Westergaard JG, Svendsen P, et al (1981). Comparison of pregnancy-associated protein-1 and human pregnancy zone protein. J Reprod Immunol, 3, 341-9.

Ichikawa K, Liu W, Zhao L, et al (2010). Tumoricidal activity of a novel anti-human DR5 monoclonal antibody without hepatocyte cytotoxicity. Nat Med, 7, 954-60.

Jo M, Kim TH, Seol DW, et al (2000). Apoptosis induced in normal human hepatocytes by tumor necrosis factor-related apoptosis-inducing ligand. Nat Med, 6, 564-67.

Kelley RF, Totpal K, Lindstrom SH, et al (2005). Receptor-selective mutants of apoptosis-inducing ligand 2/tumor necrosis factor-related apoptosis-inducing ligand reveal a greater contribution of death receptor (DR) 5 than DR4 to apoptosis signaling. $J$ Biol Chem, 280, 2205-12.
Kimberley FC, Screaton GR (2004). Following a TRAIL: update on a ligand and its five receptors. Cell Res, 14, 359-72.

Kischkel FC, Lawrence DA, Chuntharapai A, et al (2000). Apo2L/TRAIL-dependent recruitment of endogenous FADD and caspase- 8 to death receptors 4 and 5. Immunity, 12, 611-20.

Lawrence D, Shahrokh Z, Marsters S, et al. (2001). Differential hepatocyte toxicity of recombinant Apo2L/TRAIL versions. Nat Med, 7, 383-5.

Lebedeva IV, Su ZZ, Sarkar D, et al (2003). Restoring apoptosis as a strategy for cancer gene therapy: focus on p53 and mda7. Sem Cancer Biol, 13, 169-78.

LeBlanc HN, Ashkenazi A (2003). Apo2L/TRAIL and its death and decoy receptors. Cell Death Differ, 10, 66-75.

Lemamy GJ, Roger P, Mani JC, etal.(1999). Highaffinity antibodies from hen's-egg yolk against human mannose-6 phosphate/ insulin-like growth-factor-II receptor (MGP/IGFII-R): Characterization and potential use in clinical cancer studies. Int $J$ Cancer, 80, 896-902.

Leslie GA, Clem LW (1969). Phylogeny of immunoglobulin structure and functions. III. Immunoglobulins of the chicken. J Exp Med, 130, 1337-52.

Ozoren N, Kim K, Burns TF, et al (2000). The caspase 9 inhibitor Z-LEHD-FMK protects human liver cells while permitting death of cancer cells exposed to tumor necrosis factor-related apoptosis-inducing ligand. Cancer Res, 60, 6259-65.

Salcedo TW, Alderson RF, Basu S, et al (2002). TRM-1, a fully human TRAIL-R1 agonistic monoclonal antibody, displays in vitro and in vivo anti-tumor activity. Proc Annu Meet Am Assoc Cancer Res, 43, 856.

Sarker SA, Casswall TH, Juneja FL, et al (2001). Randomised, placebo-controlled, clinical trial of hyperimmunised chicken egg yolk immunoglobulin (HEY) in children with rotavirus diarrhoea. J Pediat Gastroenterol Nutr, 32, 19-25.

Schade R, Hlinak A, Marburger A, et al (1997). Advantages of using egg yolk antibodies in the life sciences: the results of five studies. ATLA-Altern Lab Anim, 25, 555-86.

Shargh SA, Sakizli M, Khalaj V, et al (2014). Downregulation of E-cadherin expression in breast cancer by promoter hypermethylation and its relation with progression and prognosis of tumor. Med Oncol, 31, 250.

Sprick MR, Weigand MA, Rieser E, et al (2000). FADD/MORT1 and caspase- 8 are recruited to TRAIL receptors 1 and 2 and are essential for apoptosis mediated by TRAIL receptor 2 . Immunity, 12, 599-609.

Svendsen L, O'Brien D, Stodulski G, et al (1994). Use of chickens and exploitation of egg yolk antibody production. In: Welfare and Science (Bunyan J ed). Royal Society of Medicine Press, London, 324-7.

Thompson CB. (1995). Apoptosis in the pathogenesis and treatment of disease. Science, 267, 1456-62.

Tini M, Jewell UR, Camenish G. (2002). Generation and application of chicken egg-yolk antibodies. Comp Biochem Physiol, 131, 569-74.

Walczak H, Miller RE, Ariail K, et al (1999). Tumoricidal activity of tumor necrosis factor-related apoptosis-inducing ligand in vivo. Nat Med, 5, 157-63.

Xiang H, Reyes AE, Eppler S, et al (2013). Death receptor 5 agonistic antibody PRO 95780: preclinical pharmacokinetics and concentration-effect relationship support clinical dose and regimen selection. Cancer Chemother Pharmacol, $\mathbf{7 5}$, $1-11$. 